\title{
Leadership, Performance, and Reputation: A multi-method empirical view on the public and nonprofit sectors - Habilitation Synopsis
}

\author{
Jurgen Willems
}

2019

Universität Hamburg,

Von-Melle-Park 9,

20146 Hamburg,

Germany,

GitHub: @MrJurgenWillems,

Twitter: @MrJurgenWillems

Note: This article is the synopsis to my cumulative Habilitation dissertation in the field of Management (Submitted and defended at the Faculty of business, economic and social sciences of the University of Hamburg; Department of Social Economics). Please contact me for the full version, including the published articles.

\section{$0.1 \quad$ Introduction}

This Habilitation dissertation combines eleven published articles for which the overall content relates to three interrelated concepts: leadership, performance, and reputation. Hence, this Habilitation contributes to the field of management by further exploring these concepts and investigating how they relate to each other. Each of the studies aims at bringing a substantial contribution to the field of management research, both from a scientific and a practice perspective. In the subsequent section, I shortly introduce these concepts, and I clarify the academic contributions made by this Habilitation for these three concepts. In the text below, there are links to the to the original articles (publishers' websites). However, if you have no access to these journals due to the pay-wall, you can request the articles on ResearchGate, and I will as soon as possible send you a copy.

The empirical analyses of the studies are situated in the context of nonprofit and public organizations. In this synopsis, I further explain how the public and nonprofit sectors form the unique setting to study these three management concepts. Studying these concepts in the nonprofit and public context has at least two major advantages. First, more sector specific recommendations can be made, taking much more their particularities into account. Second, the generalizability of managerial theories are scrutinized for this specific context. In other words, many managerial frameworks and theoretical perspectives are developed for the for-profit business context and by studying them in an alternative context where profit is not the (main) goal, makes it possible to scrutinize their general applicability. I explain this in more detail in the section The public and nonprofit sectors as scientific field.

In the section Overview of studies and contribution to the literature, I give an overview of the eleven studies in this Habilitation, and I explain how each of them contributes to the field of management research, and to public and nonprofit research in particular. The combination of studies includes a variety of theoretical perspectives, research methods, and study contexts. As a result, with this cumulative Habilitation I aim at fulfilling the prerequisite of a broad contribution to the management research field. 


\subsection{Defining Leadership, Performance, and Reputation}

Leadership is widely studied in the field of management and can be defined as "[. . . ] the ability of an individual to influence, motivate, and enable others to contribute toward the effectiveness and success of the organizations of which they are members" (House et al. 2002 , p5). Several studies in this Habilitation focus on dynamics in leadership teams. Consequently, a leadership team is the group of individuals that is actively involved in the strategic decision-making and in the main governance processes of an organization. The studies in this Habilitation contribute to the literature by exploring how dynamics within leadership teams have an influence on the other related concepts: performance and reputation. On the one hand, the articles focus on the concept of shared mental models in leadership teams and how they related to perceptions of organizational performance. On the other hand, some studies contribute to the literature by investigating power structures within leadership teams, building on the notion of dominant coalitions in organizational governance.

Organizational performance can be defined as the extent that an organization achieves it goals. However, organizational goals can be very diverse and context specific, and therefore many different forms of performance can be distinguished within this overall and abstract concept. For instance, when performance is hard to measure, subjective, and multi-dimensional - as it is the case for many public and nonprofit organizations (Herman and Renz 1999; Herman and Renz 2008; Lecy, Schmitz, and Swedlund 2012; Jun and Shiau 2012 ) - stakeholders' subjective perceptions and opinions on performance play a major role. This means that organizational performance is equal to its external reputation and is thus highly determined by the various opinions held by numerous stakeholders. Therefore, one of the articles of this Habilitation gives an in-depth theoretical exploration of the methodological trade-offs to make when operationalizing performance measures. Other studies in this Habilitation build on these trade-offs to further explore reputational dynamics among organizational stakeholders.

Reputation is defined as accumulated perceptions that stakeholders have on an organization's capacity to create value (Fombrun and Shanley 1990; Rindova et al. 2006; Rindova et al. 2005 ), and it can enhance stakeholder trust and their willingness to engage with the organization (Austin, Stevenson, and Wei-Skillern 2006). The specific component of this overall perception that focuses on performance of an organization is performance reputation (Willems, Jegers, and Faulk 2016). On the intersection of performance and reputation, the articles in this cumulative Habilitation contribute to the literature by clarifying various factors that influence reputation and perceived performance.

\subsection{The public and nonprofit sectors as scientific field}

Theory development and validation in the management research literature has still too often inherent assumptions embedded that are typical for for-profit business organizations and that cannot always be generalized for all types of organizations, including public and nonprofit organizations (Balser and McClusky 2005; Cornforth 2011; Morris et al. 2007). Despite the fact that a multitude of such un-generalizable assumptions could be listed and elaborated, I focus for the purpose of this synopsis on the embedded assumptions of primary stakeholders. In short, due to the unique and clear goal of for-profit organizations, which is primarily profit making to distribute it to the organization's owners, it is possible to distinguish two primary stakeholder types in the context of for-profit organizations. These stakeholder types can be classified as 'primary' due to their substantial and powerful role in the organizational value creation processes. These two primary stakeholder types in the for-profit context are (1) the organization's owners, who invest capital in the organization, but expect a return on investment; and (2) the organization's customers, who are willing to pay a profit margin for the added value of the organization's products or services. These two types of stakeholders are the primary stakeholders for many for-profit organizations as their decision processes determine whether business remain to exist. This means, if for some reason owners do not want to invest in the organization (anymore), or when the customer does not see added values from its products and services, the organization cannot reach its principal goal, and might stop to exist over time. As a result, the success of many business-oriented theories and practice recommendations can been traced back to their ability to explain how return on investment for owners and/or added value for customers is created and increased. 
However, public and nonprofit organizations, which are (partially) defined by the non-distribution constraint which means that their goals do not include the distribution of profit to owners (Hansmann 1987), do not have formal owners. Moreover, as their goals focus on social, environmental and public aspects, the ones paying for the organization's services and products are seldom the ones benefiting from it (Brooks 2003 ; Callen 1994 ; Foster, Kim, and Christiansen 2009) . As a result, many public and nonprofit organizations have no clear one-on-one customer relationships with their stakeholders in which a profit margin is exchanged for added value. In other words, even without customers and formal owners, public and nonprofit organization can remain to exist and even be very successful in achieving their specific goals. However, the consequences are that (1) public and nonprofit organizations often combine a broader variety of stakeholders, including donors, beneficiaries, volunteers, members, employees, policy makers, and citizens; and (2) that power relationships among these stakeholders are often less hierarchical and one-directional compared to for-profit organizations.

It are in particular these two consequences that make it challenging to study concepts of leadership, performance, and reputation in the public and nonprofit context. For example, board members in organizational governance bodies, have not to the same extent the responsibility to represent benefits of a single type of stakeholder. As a result, seminal contributions have argued that theoretical models on for-profit board leadership are to a varying extent applicable to public and nonprofit settings (Parker 2007, Cornforth (2011)). In contrast, their responsibilities might be substantially broader, as they represent different types of stakeholders (Van Puyvelde et al., 2012). Moreover, as organizational goals of public and nonprofit organizations are not profit-driven, pro-social aspect often play a major role. This means that leadership decisions should also cover broader responsibilities such as the management of volunteers, citizen participation, membership relations, etc. Similarly, not all business theories that are successful in explaining customer and (paid) employee behavior might to the same extent be successful in explaining and managing stakeholder behaviors in the public and nonprofit contexts.

The observation that the stakeholder range can be broader and more lateral in public and nonprofit settings has also important consequences on the study of public and nonprofit performance. In short, public and nonprofit organizations combine a series of goals within their overall mission that cover the various preferences of multiple stakeholder types. As a result, several organizational goals might be complementary to each other, but might also be traded of against each other when scarce resources have to be allocated for the achievement of these goals (Lecy, Schmitz, and Swedlund 2012 ; Willems, Boenigk, and Jegers 2014). This multi-goal setting complicates in many cases public and nonprofit performance. As different dimensions might have different importance for different stakeholders, performance evaluations of public and nonprofit organizations are very subjective. Moreover, as public and nonprofit goals are often shared with other public and nonprofit organizations, it is also difficult or impossible to clearly delineate the contribution of each organization in social and public goal achievement. For example, it the contexts of poverty reduction or environment protection it is impossible to clearly quantify the unique contribution of a single organization (Coleman Selden and Sowa 2004; Sowa, Selden, and Sandfort 2004). Therefore, leadership in public and nonprofit is also strongly focused on intra- and inter-sector collaborations to achieve such shared goals. Hence, due to the high subjectivity and difficulty to quantify public and nonprofit performance, the academic debate is still vivid on what constitutes true public and nonprofit performance. In contrast, as subjectivity and social constructionism are inherent for public and nonprofit performance, reputation and perceptions are in many cases substantially more important than true performance (Herman and Renz 2008 ; Willems, Boenigk, and Jegers 2014) .

As a result, theoretical management models and practical recommendations that are built tacitly or explicitly on owner or customer benefits, might not work in public and nonprofit contexts where these relationships are not primary. In other words, humans act differently in many ways when they have the role of owner or customer in some contexts, and the role of citizen, volunteer, or community member in other contexts.

In sum, studying management concepts in the area of public and nonprofit organizations has, at least in my opinion, two major benefits for the derivation of practice recommendations on the one hand, and management theory development on the other hand. First, there is a continuous need to develop sector specific insights that explicitly take the uniqueness of the public and nonprofit sectors into account. Practical recommendations that are derived from theoretical models that work to understand the roles we have as owner and customer, might not always to the same extent work, or even work contra-productively, to understand the roles we have 
as citizen, volunteer, members, etc. Therefore, an explicit research focus on public and nonprofit organization and the roles we have in relation to them, with sufficient attention to their unique sectorial characteristics, can substantially help in formulating practical recommendations that account for these characteristics. Therefore, the articles in this habilitation contribute to the literature by focusing on some of these specific stakeholder roles such as citizens, members, volunteers, and patients.

Second, a stronger focus on the public and nonprofit organizations to study management concepts can also advance the general management research field from a scientific perspective. Many management science theories and frameworks have to a varying extent assumptions embedded of strong primary stakeholders. By actively questioning - both theoretically and empirically - the applicability of this variety of business-based insights in the alternative contexts of public and nonprofit organizations, their true generalizability and robustness is put to the test. This means that actively looking at managerial challenges that occur specifically in public and nonprofit organization cannot only result in more focused practical recommendation, it provides the necessary sensitivity and robustness evaluation of the theoretical lens that is taken.

\subsection{Overview of studies and contribution to the literature}

The eleven articles of this cumulative Habilitation dissertation are conceptually and methodologically related in the following way.

\subsubsection{The link between leadership concepts and performance reputation}

Articles 1, 2, and 3 contain three quantitative analyses of three different survey databases, and each deals with an aspect of how leadership and leadership team dynamics relate to perceptions on organizational performance. Article 4 complements these studies in a qualitative way by elaborating the power structures among leaders. More explanation per article is given in the respective paragraphs below.

Article 1 (Willems 2016b) explores which governance practices nonprofit leaders consider necessary to avoid organizational crises. Further, it explores whether these leadership mental models of crisis resistance depend on the organizational context. This helps determine whether practical learning points are organization specific or can be applied broadly to any kind of (nonprofit) organization. With a multilevel sample of 304 leaders from 44 Belgian nongovernmental development organizations, an exploratory path analysis reveals that nonprofit leaders consider continuous improvement - as a governance practice - particularly relevant for effective organizational crisis resistance. A multilevel analysis also shows that variations in leadership mental models cannot be explained by the organizational variables used in this study (organizational size, leadership group size, operational activities, and languages in the leadership group).

Article 2 (Willems 2016a), elaborates the insights from Article 1 by exploring in more depth the concept of shared mental models among leaders. Because shared mental models are critical for consistent, accurate decision making, this study seeks to explain the extent to which mental models are shared on the basis of team cognition theory and social constructionism. This study thus provides new insights into how the social dynamics among nonprofit leaders can explain mental models on nonprofit performance (i.e. internal performance reputation). Specifically, team member exchange (TMX) quality should relate to agreement within leadership teams. Building on recent multilevel team research methods, this study regards the relationship theoretically as a separate actor and partner effect, which better reveals the underlying social processes of shared mental models. With another multilevel data sample of 402 leaders from 44 nonprofit organizations, this time not limited to nongovernmental development organizations (See Article 1), the hypotheses are tested. Confirmation of the hypotheses offers insights into the multilevel, emergent nature of team behavior and shared mental models.

Article 3 (Valéau, Willems, and Parak 2016) complements Articles 1 and 2 by incorporating individual motivations of volunteers and employees that participate on the organizational decision processes. Using a multilevel analysis including 207 volunteers and paid workers nested within 51 French nonprofit organizations from the French oversees Department La Réunion, this study examines the effect of individual and group 
attitudinal and behavioral commitment on their assessment of organizational performance. Drawing on classical attitude theories, our results indicate that individuals with higher affective organizational commitment tend to assess their NPO's effectiveness higher, while individuals staying because of the lack of alternatives assess it lower. However, in line with behavioral commitment theories, both relationships are mediated by the effect of teamwork behavioral commitment. We also found a negative effect of normative attitudinal commitment partially nested at the group level. Overall, our results suggest that encouraging volunteers and paid workers to participate in concrete teamwork behaviors on a daily basis constitutes a twofold benefit: it adds to the effect of affective attitudinal commitment at the individual level, while counter balancing the negative effects related to normative individual and collective resistances.

Article 4 (Willems et al. 2017) takes qualitative approach to leadership dynamics by framing it in the organizational literature on dominant coalitions in leadership teams. In doing so, we answer the call that nonprofit governance research should focus more on processes outside the boundaries of governance boards, especially for nonprofit organizations. In particular, we suggest and elaborate concrete steps with respect to the advantages of a leadership coalition perspective to focus more on the behavioral and informal aspects of governance. Through a comparative case analysis of five nonprofit organizations, we explore contingencies between characteristics of nonprofit leadership coalitions and governance quality. We identify two dimensions to classify leadership coalitions: centralized versus diffused influence and specific versus holistic influence. These dimensions are subsequently related with observed governance quality. We frame our finding in the existing literature on group faultlines, which are socially constructed dividing lines within groups, and we discuss the importance of establishing a balanced coalition between a weak or non-existing and a strong dominant coalition to ensure high governance quality. We also present propositions on how governance quality and its various sub-dimensions can be studied as a complex, nonlinear intermediate concept between coalitional aspects of leadership groups and nonprofit organizational performance.

\subsubsection{Further exploring and applying the concept of performance reputation}

Articles 5 to 7 focus on the perceptions that internal and external stakeholders have on organizational performance and functionality. Article 5 gives a theoretical overview of the choices to be made when measuring nonprofit performance or perceptions about it. Articles 6 and 7 respectively elaborate concepts of stakeholder perceptions in the hospital and (non-formal) educational sectors.

Article 5 (Willems, Boenigk, and Jegers 2014) presents seven trade-offs for researchers and practitioners to consider before engaging in a nonprofit performance measurement project. By presenting these seven trade-offs, this theory-driven study complements contemporary performance literature, which mainly offers theory-driven recommendations for measuring nonprofit effectiveness, performance, or related concepts. For each trade-off, we offer examples and suggestions to clarify the advantages and disadvantages of methodological choices that take various contextual elements into account. In particular, we address the differences between formative and reflective approaches, as well as the differences between unit of interest, unit of data collection, and unit of analysis. These topics require more in-depth attention in the nonprofit performance literature to avoid misinterpretations and measurement biases. Finally, this article concludes with five avenues for further research to help address key challenges that remain in this research area.

Article 6 (Willems 2015) focuses on stakeholder perceptions for a particular type of organizations. Non-formal education is often one of the organizational goals of many public and nonprofit organizations, and this study explores how the availability of resources for stakeholders influences their perceptions on non-formal education. Hence, the aim of this study is to explore the extent that country-level developmental characteristics can explain perceived functionalities of local non-formal education. A literature-based distinction is made between participant functionality (inward focused) and societal functionality (outward focuses) of non-formal education. An empirical test is conducted for the international scouts and guides movement based on a sample of 2,735 respondents from 68 countries. The results of a multi-level regression analysis suggest a crowding-out relationship between developmental capacity, quantified by the human development index (HDI), and societal functionality. In contrast, participant functionality remains constant despite differences between countries for the HDI. 
Article 7 (Willems and Ingerfurth 2018), similarly to Article 6 focuses on stakeholder perceptions for a particular type of organizations. However, this time the focus is on patients' and employees' perceptions on hospital performance. To assess hospital performance, quality perceptions of various stakeholders are increasingly taken into account. However, because of substantial background differences, various stakeholder groups might have different and even contrasting quality perceptions. We test the hypothesis that an overall perception gap exists between employees and patients with respect to perceived hospital quality. We additionally elaborate on how various employee groups differ from each other and from patients. We use primary survey data on perceived hospital quality from 9,979 patients and 4,306 employees from 11 German hospitals. With a multilevel regression and variance analysis, we test the impact of respondent type (employee or patient) on quality perception scores and test the interaction with hospital size. We additionally contrast different employee groups and test differences for various quality dimensions. Hospital employees score hospital quality consistently lower than patients and are also more heterogeneous in their assessments. This makes it from a managerial point of view relevant to subdivide employees in more homogeneous subgroups. Hospital size has no clear effect on the perception gap. Doctors compared to patients and other employee groups have substantially different perceptions on hospital quality.

\subsubsection{Further exploring specific challenges of the public and nonprofit sectors}

As pointed out above, leadership and performance reputation are concepts that need special attention in the nonprofit and public sectors. Along with these challenges, these sectors are additionally typified by the unique leadership challenges to manage collaborators inside the organization, and to govern collaborations outside the organizations. Within that context, Articles 8 and 9 elaborate on some specific challenges of human resource leadership in the public and nonprofit sectors, while Articles 10 and 11 elaborate on how organizational performance (or performance reputation) is influenced by intra- and inter sector collaborations.

Given the unique role of prosocial motivation and behavior in the public and nonprofit sectors, in Article 8 (Willems and Walk 2013) we aim to explore the relationship between volunteer motives and task preferences in order to provide volunteer managers with better insight in how tasks can be assigned to keep youth volunteers satisfied. Earlier seminal contributions have either taken a pure functional approach - where various types of motives are supposed to be at the base of any type of volunteer work - or a differentiated approach, where particular motives relate to specific task preferences. However, empirical results reported in the literature do not justify the preference of one approach above the other. To investigate whether one of the approaches is superior, or whether a combination of both is more appropriate, we perform a canonical correlation analysis for a set of functional motives and a set of task preferences $(\mathrm{N}=2,158)$. Five distinct relationships (canonical variate pairs) of motives and preferences are found. Results show that a 'functional basis' exists where all motives relate to a basic set of tasks. Additionally, a more differentiated approach towards volunteer motives and task preferences has to be taken, as we find four other relationships where specific motives are satisfied by assigning particular sets of tasks.

While Article 8 focusses on volunteers, Article 9 (Willems 2014) focuses on motivational aspects of employees in the nonprofit and public sectors, compared to the for-profit sector. In this study, I postulate a complementary consideration to an article of LeRoux and Feeney 2013. The aim is to provide avenues for further research on employee research in the public and nonprofit sectors based on an evaluation of the embedded assumptions on causality and interdependency of the variables used. I perform an extended empirical analysis of the same data as used in LeRoux and Feeney (2013) in which inherent assumptions are adjusted based on available literature. Results show that their conclusions need nuancing, and that further research could focus on (1) a clearer distinction between antecedents and effects of sector of employment, and (2) the different relationships across sectors between work-related variables, such as job satisfaction, job flexibility, or job clarity.

The study in Article 10 (Faulk et al. 2016) investigates whether nonprofit board connections with other nonprofit organizations and foundations explain organizational performance in earning foundation grants. Using a sample of 402 nonprofits and sixty-eight foundations in a single metropolitan area in the US, we find that greater connectedness and status interlocks significantly influence organizations' ability to acquire resources. Network effects are partially mediated by the number of past grants received and a nonprofit's financial characteristics, including organizational size, fundraising expenses, and financial health. These 
findings, while supporting the role of networks in resource attainment, point to the complex and mutual relationships between organizational characteristics, network characteristics, and organizational performance.

Article 11 (Crispeels, Willems, and Scheerlinck 2018) focuses also on the role of organizational collaborations on performance. Consistent with popular belief among certain academics, practitioners, and policy makers, we hypothesize that collaboration between private and public organizations promotes success. We test this hypothesis for data on clinical trial success. Contrary to this popular belief, our results do not support the beneficial effect of within- and cross-sector collaborations. In contrast, we find that trials from single private companies are four times more likely to be successful than are trials in which public and private organizations collaborate. Hence, our results indicate that companies engage with public partners to mitigate development risks, not to exchange knowledge or technologies with them

\section{References}

Austin, James, Howard Stevenson, and Jane Wei-Skillern. 2006. "Social and Commercial Entrepreneurship: Same, Different, or Both?" Entrepreneurship: Theory and Practice 1 (1): 1-22. doi:10.1111/j.15406520.2006.00107.x.

Balser, Deborah, and John McClusky. 2005. "Managing Stakeholder Relationships and Nonprofit Organization Effectiveness." Nonprofit Management \& Leadership 15 (3): 295-315. doi:10.1002/nml.70.

Brooks, Arthur C. 2003. "Do Government Subsidies to Nonprofits Crowd Out Donations or Donors?" Public Finance Review 31: 166. doi:10.1177/1091142102250328.

Callen, Jeffrey L. 1994. "Money Donations, Volunteering and Organizational Efficiency." The Journal of Productivity Analysis 5 (3): 215-28.

Coleman Selden, and Jessica E. Sowa. 2004. "Testing a Multi-Dimensional Model of Organizational Performance: Prospects and Problems." Journal of Public Administration Research and Theory 14 (3): $395-416$.

Cornforth, Chris. 2011. "Nonprofit Governance Research: Limitations of the Focus on Boards and Suggestions for New Directions." Nonprofit and Voluntary Sector Quarterly 41 (6): 1116-35. doi:10.1177/0899764011427959.

Crispeels, Thomas, Jurgen Willems, and Ilse Scheerlinck. 2018. "Public-Private Collaborations in Drug Development: Boosting Innovation or Alleviating Risk?" Public Management Review 20 (2): 273-93. doi:10.1080/14719037.2017.1302247.

Faulk, Lewis, Jurgen Willems, Jasmine McGinnis Johnson, and Amanda J. Stewart. 2016. "Network Connections and Competitively Awarded Funding: The Impacts of Board Network Structures and Status Interlocks on Nonprofit Organizations' Foundation Grant Acquisition." Public Management Review 18 (10): 1425-55. doi:10.1080/14719037.2015.1112421.

Fombrun, Charles, and Mark Shanley. 1990. "What's in a Name? Reputation Building and Corporate Strategy." Academy of Management Journal 33 (2): 233-58. doi:10.2307/256324.

Foster, William Landes, Peter Kim, and Barbara Christiansen. 2009. "Ten Nonprofit Funding Models." Stanford Social Innovation Review, -.

Hansmann, Henry. 1987. "Economic Theories of Nonprofit Organizations," 27-42.

Herman, Robert D., and David O. Renz. 1999. "Theses on Nonprofit Organizational Effectiveness." Nonprofit and Voluntary Sector Quarterly 28 (2): 107-26. doi:10.1177/0899764099282001.

- 2008. "Advancing Nonprofit Organizational Effectiveness Research and Theory: Nine Theses." Nonprofit Management \& Leadership 18 (4): 399-415. doi:10.1002/nml.195.

House, Robert, Mansour Javidan, Paul Hanges, and Peter Dorfman. 2002. "Understanding Cultures and Implicit Leadership Theories Across the Globe: An Introduction to Project Globe." Journal of World Business 
37 (1): $3-10$.

Jun, Kyu-Nahm, and Ellen Shiau. 2012. "How Are We Doing? A Multiple Constituency Approach to Civic Association Effectiveness." Nonprofit and Voluntary Sector Quarterly 41 (4): 632-55.

Lecy, Jesse D., Hans Peter Schmitz, and Haley Swedlund. 2012. "Non-Governmental and Not-for-Profit Organizational Effectiveness: A Modern Synthesis." Voluntas: International Journal of Voluntary and Nonprofit Organizations 23 (2): 434-57.

LeRoux, Kelly, and Mary K. Feeney. 2013. "Factors Attracting Individuals to Nonprofit Management over Public and Private Sector Management." Nonprofit Management and Leadership 24 (1): 43-62.

Morris, Michael H., Susan Coombes, Minet Schindehutte, and Jeffrey Allen. 2007. "Antecedents and Outcomes of Entrepreneurial and Market Orientations in a Non-Profit Context: Theoretical and Empirical Insights," -

Parker, Lee D. 2007. "Boardroom Strategizing in Professional Associations: Processual and Institutional Perspectives." Journal of Management Studies 44 (8): 1454-80.

Rindova, Violina P., Ian O. Williamson, Antoaneta P, Petkova, and Joy Marie Sever. 2006. "Celebrity Firms: The Social Construction of Market Popularity." Academy of Management Review 31 (1): 50-71.

Rindova, Violina P., Ian O. Williamson, Antoaneta P. Petkova, and Joy Marie Sever. 2005. "Being Good or Being Known: An Empirical Examination of the Dimensions, Antecedents, and Consequences of Organizational Reputation." Academy of Management Journal 48 (6): 1033-49.

Sowa, Jessica E., Sally Coleman Selden, and Jodi R. Sandfort. 2004. "No Longer Unmeasurable? A Multidimensional Integrated Model of Nonprofit Organizational Effectiveness." Nonprofit and Voluntary Sector Quarterly 33 (4): 711-28. doi:10.1177/0899764004269146.

Valéau, Patrick, Jurgen Willems, and Hassan Parak. 2016. "The Effect of Attitudinal and Behavioral Commitment on the Internal Assessment of Organizational Effectiveness: A Multilevel Analysis." Voluntas: International Journal of Voluntary and Nonprofit Organizations 27 (6): 2913-36. doi:10.1007/s11266-0169703-6.

Willems, Jurgen. 2014. "Antecedents or Effects of Being a Manager in the Nonprofit, Public or Private Sector." Nonprofit Management $\&$ Leadership 25 (2): 183-89.

- 2015. "Individual Perceptions on the Participant and Societal Functionality of Non-Formal Education for Youth: Explaining Differences Across Countries Based on the Human Development Index." International Journal of Educational Development 44: 11-20. doi:10.1016/j.ijedudev.2015.07.003.

- 2016a. "Building Shared Mental Models of Organizational Effectiveness in Leadership Teams Through Team Member Exchange Quality." Nonprofit and Voluntary Sector Quarterly, -. doi:10.1177/0899764015601244.

—. 2016b. "Organizational Crisis Resistance: Examining Leadership Mental Models of Necessary Practices to Resist Crises and the Role of Organizational Context." Voluntas: International Journal of Voluntary and Nonprofit Organizations 27 (6): 2807-32. doi:10.1007/s11266-016-9753-9.

Willems, Jurgen, and Stefan Ingerfurth. 2018. "The Quality Perception Gap Between Employees and Patients in Hospitals." Health Care Management Review 43 (2): 157-67. doi:10.1097/HMR.0000000000000137.

Willems, Jurgen, and Marlene Walk. 2013. "Assigning Volunteer Tasks: The Relation Between Task Preferences and Functional Motives of Youth Volunteers." Children and Youth Services Review 35 (6): 1030-40. doi:10.1016/j.childyouth.2013.03.010.

Willems, Jurgen, Fredrik O. Andersson, Marc Jegers, and David O. Renz. 2017. "A Coalition Perspective on Nonprofit Governance Quality: Analyzing Dimensions of Influence in an Exploratory Comparative Case 
Analysis." Voluntas: International Journal of Voluntary and Nonprofit Organizations 28 (4): 1422-47. doi:10.1007/s11266-016-9683-6.

Willems, Jurgen, Silke Boenigk, and Marc Jegers. 2014. "Seven Trade-Offs in Measuring Nonprofit Performance and Effectiveness." Voluntas: International Journal of Voluntary and Nonprofit Organizations 25 (6): 1648-70. doi:10.1007/s11266-014-9446-1.

Willems, Jurgen, Marc Jegers, and Lewis Faulk. 2016. "Organizational Effectiveness Reputation in the Nonprofit Sector." Public Performance and Management Review 39 (2): 476-97. doi:10.1080/15309576.2015.1108802. 